\title{
Designing Learning Experiences: Supporting Teachers in the Process of Technology Change
}

\author{
Barry Harper \\ Faculty of Education, University of Wollongong \\ barry_harper@uow.edu.au
}

Abstract: As teachers adopt technology in their classrooms and develop the pedagogical models that will allow them to make use of the affordances of the technology, we are seeing improved learning outcomes and high-quality learning demonstrated. The pedagogical models that are showing the most promise come from ideas about how designers can implement the class of theories referred to as constructivism. Designers of technology-based learning environments can draw on the work of the many writers who have sought to develop guidelines and heuristics to support new modes of learning (see for example, Grabinger, 1996; Hannafin \& Land, 1997; Squires, 1996). Constructivist frameworks are based upon the argument for learners being placed in authentic environments that incorporate sophisticated representations of context through such constructs as virtual "worlds". Learning experiences, which adopt these approaches, designed around bounded resources, such as CD-ROM technologies, are now well documented and many teachers have been making extensive use of these environments for some time. One such project, Exploring the Nardoo, which has been developed within constructivist frameworks as a virtual world has been acclaimed for its illustration of these concepts. The product displays varying degrees of fidelity of representation, learner immersion and active participation and has been shown to offer learning advantages for users.

However, teachers need to continue to address the constantly changing nature of the capability of the technology, and potential learning opportunities offered by these changes. Unbounded environments, such as the World Wide Web, have offered a new set of affordances and now the concept of learning objects is set to again require teachers to re-conceptualise learning experiences for their students. The concept of a 'learning object' has developed from the movement to create reusable learning resources. Significant investment in content, described in terms of standards, which can be reused and re-purposed in education settings, is becoming a priority nationally (The Le@rning Federation, http://socci.edna.edu.au/newcms/view_page.asp) and internation-

The original version of this chapter was revised: The copyright line was incorrect. This has been corrected. The Erratum to this chapter is available at DOI: 10.1007/978-0-387-35701-0_35 
ally (Ariadnc: http://ariadne.unil.ch/, Merlot: http://taste.merlot.org/, LRX: http://www.Irx.com.au/). Teachers are now seeking tools to make effective use of the myriad of learning objects that are now being developed, in such entities as digital libraries, to construct meaningful learning environments.

This paper will review the changes in pedagogy which ICT based learning environments have been able to facilitate, report on research findings on learning outcomes for a series of innovative bounded CD-ROM learning environments, and review the potential of learning object technologies to again challenge teachers striving for high quality learning from their students.

\section{INTRODUCTION}

As teachers adopt technology in their classrooms, safe in the understanding that the weight of argument and evidence supports pedagogy, not the technology (Clarke, 1985, 1999), as the key to successful learning design, we are seeing the development of pedagogical models which will allow teachers to make use of the affordances of the technology. The pedagogical models which are showing the most promise in demonstrating improved learning outcomes and high quality learning come from ideas about how designers can implement contemporary theories of learning which support knowledge construction through learner-centred settings (e.g. Bostock, 1998; Duffy \& Cunningham, 1996) via activity-based tasks and collaborative learning which are scaffolded and supported by teachers or tools (e.g. Vygotsky, 1978). Designers of technology-based learning environments can draw on the work of the many writers who have sought to develop guidelines and heuristics to support new modes of learning (see for example, Grabinger, 1996; Hannafin and Land, 1997; Squires, 1996). These frameworks are based upon the argument for learners being placed in authentic environments that incorporate sophisticated representations of context through such constructs as virtual worlds. Learning experiences that adopt these approaches, designed around bounded resources, such as CDROM technologies, are now well documented, and many teachers have been making extensive use of these environments for some time.

However, teachers need to continue to address the constantly changing nature of the capability of the technology, and potential learning opportunities offered by these changes. Unbounded environments, such as the World Wide Web, have offered a new set of affordances. With this development broader concepts about learner-learner interactions have been illustrated and are being implemented through a broad range of curriculum initiatives. This access to rich resources from world-wide sources has resulted in significantly wider use of technology, but has also helped to drive the broader view of reusability. 
The current significant investment in content, described in terms of standards, which can be reused and re-purposed in education settings, is becoming a priority nationally and internationally. The resulting construct of 'learning objects' is set to again require teachers to re-conceptualise learning experiences for their students. Teachers are now seeking tools and exemplars to construct meaningful learning environments through making effective use of the myriad of learning objects that are now being developed, in such entities as digital libraries.

This paper will review the changes in pedagogy which ICT based learning environments have been able to facilitate, report on research findings on learning outcomes for a series of innovative bounded CD-ROM learning environments, and review the potential of learning object technologies to again challenge teachers striving for high quality learning from their students.

\section{BOUNDED LEARNING ENVIRONMENTS}

Exploring the Nardoo (1996) is an innovative project that illustrates the development of learning environments based on contemporary theoretical constructs. This project was developed as a virtual world and has been acclaimed for its illustration of these concepts. The product displays varying degrees of fidelity of representation, learner immersion and active participation and has been shown to offer learning advantages for users. Exploring the Nardoo (Harper et al., 2000a, 2000b; Hedberg et al., 1998a, 1998b) has been well described and has been the focus of a number of specific studies in classrooms which have investigated learner response, the use of genre embedded templates and simulations and problem solving. The learning environment is characterised by a research centre (Figure 1) within the context of an inland river environment. A set of cognitive tools (Harper et al., 2000) supports learners in their investigation of authentic problems, with a rich set of resources as reference sources.

In an initial investigation of a broad view of learner response to the package, a structured and an ill-structured problem were set for two groups of year nine students and the construction of ideas by collaborative pairs of students was logged. Details of the study have been reported in Harper et al. (2000). Students perceived the rich tasks as being in context, motivating and worth spending a significant amount of time to develop possible solutions to the investigations. Students needed minimal instruction in the use of the cognitive tools and they developed extended arguments with multiple solutions to the investigations undertaken. In general, the ill-structured 
problem group did produce more complex and complete solutions to the task. As they did not have a defined task to solve but rather had to generate a series of hypotheses, they sought to be comprehensive and complete. More often, the structured problem group, sought to answer only the questions asked of them, and did not seek to find alternative explanations or to find other issues embedded in the investigation.

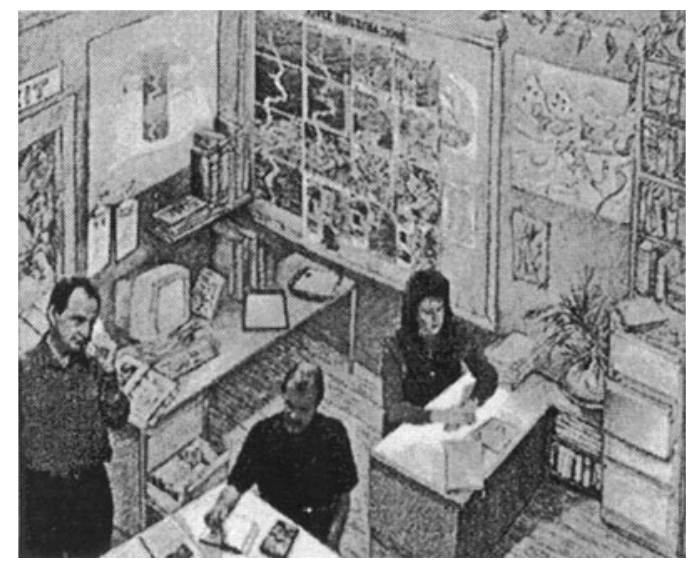

Figure 1. The Water Research Centre of Exploring the Nardoo

Gordon (1998) showed in her study that students who used the genre template cognitive tool, scored higher on learning outcome measures than students who did not. While the results endorsed the value of the templates in supporting student reporting, the static nature of the templates only improved the structure of the reports and not the quality of the arguments chosen. Further work on the development of more context sensitive assistance to improve reflection and assessment of the quality of the responses generated is underway and is showing promising results.

A study focused on probing learner problem solving to support design of more appropriate learner assistance for this package (Brickell, 2002) has reported on the use of a variety of support frameworks to assist learners in arguing their solutions, with the support frameworks resulting in greater learner achievement when using the package.

Corderoy (2002) in investigating the use of the algal bloom simulator by students has found an improvement in the process and success of formation of new knowledge links (knowledge acquisition) for students who study an ecological process (blue-green algal bloom development), using the interactive multimedia-based simulation of these processes as opposed to those who study them using rich resources without access to the simulator. $\mathrm{He}$ has also reported an improvement in the level of understanding of 
relationships (cause/effect) for students who study the ecological process using the simulators.

The range of studies reported has probed specific aspects of an individual package. However, they do illustrate improved learning outcomes when learners are engaged with learning environment designs based on contemporary views of learning, where the designs make use of the affordances of the technology, but are focused on theoretical constructs which lead to effective pedagogy.

\section{UNBOUNDED LEARNING ENVIRONMENTS}

Unbounded environments, such as the World Wide Web, are now offering a new set of pedagogical opportunities, especially in information access and collaborative processes. This technology shows particular promise for supporting meaningful learning through flexible delivery modes and a capacity to link and connect those involved in the learning process (e.g. Duschatel \& Spahn, 1996; Levin, 1999). However, pedagogical issues have often been overshadowed by developments in the technology and unfounded claims of outstanding success attributed to use of the technology seem to be just as prevalent during the development of this technology as with previous new technologies. Salomon (1998) supported this concern and has noted that for the first time in history, technologies are outpacing pedagogical and psychological rationale for design of high quality learning.

Despite the possibilities existing for rich electronic learning based on this technology, for the most part, pedagogically sound and exciting Web courseware tools have yet to be developed to take advantage of such opportunities. Nevertheless, broader concepts about learner-learner interactions have been illustrated and are being implemented through a broad range of curriculum initiatives not only at the school level, but also at the higher education level where there is a different focus. Additionally, a body of literature is starting to report on innovative tools, with strong pedagogical underpinning. Bonk (1998) has reported on interactive tools for on-line portfolio feedback, profile commenting, and Web link rating, while Oliver and McLoughlin (1999) are building tools for on-line debate, reflection, concept mapping and student surveying and discussion.

A number of international initiatives have been developed to help illustrate good pedagogy and to support instructors in incorporating these exemplars into higher education courses, including teacher preparation. Significant projects that are informing the process currently include: 
- Merlot, a database of small and large-scale interactive learning elements (http://taste.merlot.org/),

- the Ariadne project, which created tools and methodologies for producing, managing and reusing computer-based pedagogical elements and telematics supported training curricula (http://ariadne.unil.ch/), and

- the SoURCE project which identifies existing technology-based learning materials that have been shown to be successful and to replicate the successful environments as generic tools for teachers in other settings (http://www.source.ac.uk/).

An Australian University Teaching Committee (AUTC) project making some impact in this area, ICT-Based Learning Designs (www.learningdesigns.uow.edu.au) has recently been launched. The aim of this project is to assist university teachers in creating high quality flexible learning experiences for students by providing a range of generic resources/tools/templates that draw upon successful flexible learning projects that utilise ICT and which may be generalised beyond the scope of the individual project. Successful ICT-based learning projects are those that demonstrate improved learning outcomes.

The study conducted by Alexander and McKenzie (1998) highlighted that one contributing factor towards a successful learning outcome for an ICT-based learning project was the learning design employed. Thus, this project strove to accomplish its aim through the following process:

- the identification of a range of learning designs that have been demonstrated to contribute to high quality learning experiences and which can be applied generically;

- the design and subsequent development of a series of re-useable software, templates and/or exemplars for the learning designs previously identified; and

- the development of a series of guidelines for good practice in the use of or implementation of the software, templates and/or exemplars in new contexts.

Crucial to the success of this project was the development of an evaluation instrument, the Evaluation and Redevelopment Framework (ERF), with a twofold purpose:

- to facilitate the identification of learning designs that foster high quality learning experiences; and

- to provide a mechanism to determine whether such learning activity designs have the potential for re-development in a more generic form.

One of the initial activities of the project, to facilitate the development of the ERF, involved determining what constitutes "high quality learning". Two 
key researchers in the field of learning in higher education, David Boud and Mike Prosser, were commissioned to develop a paper on high quality learning. Their ideas together with feedback from the project team led to the development of a set of "Key Principles for High Quality Student Learning in Higher Education - From a Learning Perspective" (Boud \& Prosser, 2001). The four principles, which are holistic in that they incorporate both learning outcomes and learning processes, describe key characteristics that underpin high quality learning in the higher education context. The principles are based upon an experience-based learner-centred view of learning and consist of learner engagement, acknowledgement of context, challenging learners and practice. The principles can be more fully described as: -

\section{Engage learners through:}

- building on their learning intents generally and their particular expectations of the activity in question;

- acknowledging and taking account of their prior experience, both their knowledge and experience of situations which might impinge on the present ones;

- mobilising their will and desire and developing some kind of emotional engagement with the task in hand;

- providing them with a sense of agency with respect to the activity or significant parts of it; and

- recognising that learning is a social act and involves other learners for at least part of the activity.

\section{Acknowledge context through:}

- involvement with problems in context;

- recognising the context of the learner (who may see themselves as decontexualised);

- maintaining an awareness of the cultural assumptions and stereotyping which may be incorporated in the context;

- situating learning tasks within disciplinary or professional or practical knowledge as appropriate;

- taking account of the site of application of what is to be learned (this poses different challenges when the learner is currently engaged in the site of application and when they are not);

- appreciating the knowledge demands on students and equipping them to deal with them; and

- ensuring that there is a clear alignment between the activities in which students will be engaged and the ways in which they will be assessed. 


\section{Challenge learners through:}

- prompting them to seek and discern variation in the knowledge and experiences in which they are involved;

- questioning the assumptions they bring to the activity and the assumptions they develop through it;

- encouraging them to see what is provided as a means to wider ends and go beyond what is provided; and

- creating situations in which they are required to take responsibility for their own learning and to shape the activity to their own ends.

\section{Involve practice through:}

- demonstrating what has been learned for themselves and for others;

- gaining feedback at strategic points in learning, but also recognising that finding ways of gaining feedback for one self other than that provided is also important;

- reflecting on and making sense of their experiences. Continuous exposure to new activities without integration and consolidation within the learner's framework is not conducive to good learning; and

- developing confidence in performance from practice.

The ERF tool has been applied to a significant number of learning designs submitted to the project and the analysis has been used to select a range of projects considered to have the potential to support the key principles and be redeveloped as generic designs. The project has been published through a web environment with mechanisms for instructors to access the learning design exemplars, re-usable software, templates, tools etc, and guidelines for good practice in the use of or implementation of the software, templates and/or exemplars in new contexts. Additionally, the designs will be represented through a visual representation which draws from the work of Oliver (1999) and Herrington (2001), to illustrate the learning design in a temporal format (Figure 2).

The rationale for this construct is to provide a common form of communication to explain and illustrate each different kind of learning design and highlight its key features. Figure 3 illustrates this concept where the resources, learner activity or task and the learner support are all considered as separate, but essential components of a learning design. This representation of the designs has been developed to help link the resources to the issue of reusability, both of the learning design, and the learning resources described as resources or supports. 


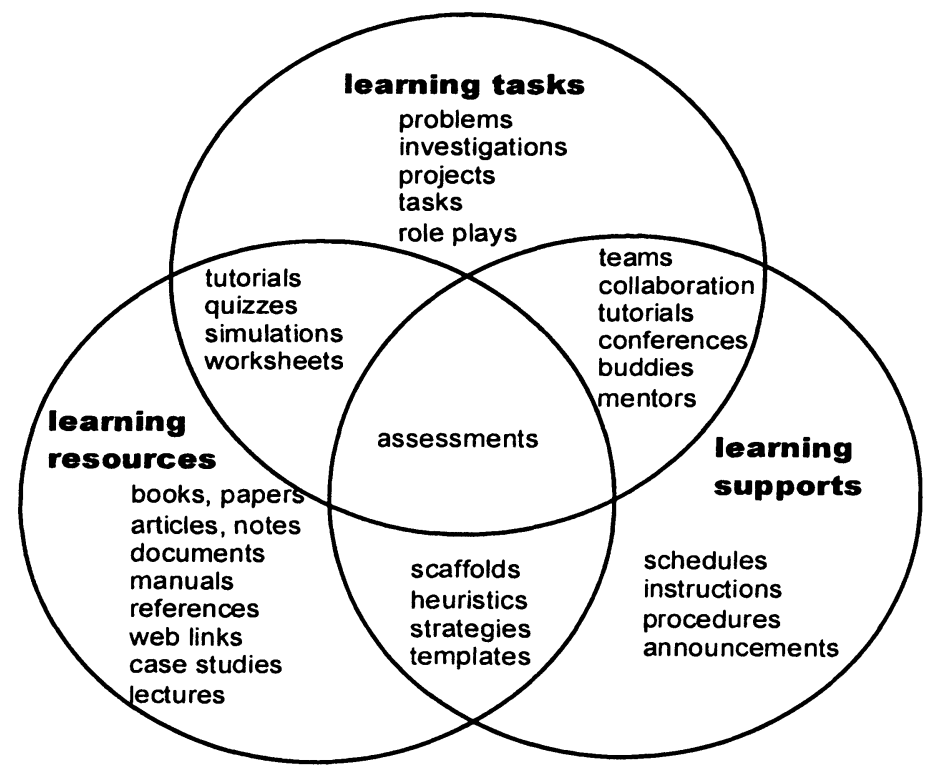

Figure 2. Elements of a learning design (based on Oliver, 1999 and Oliver \& Herrington, 2001)

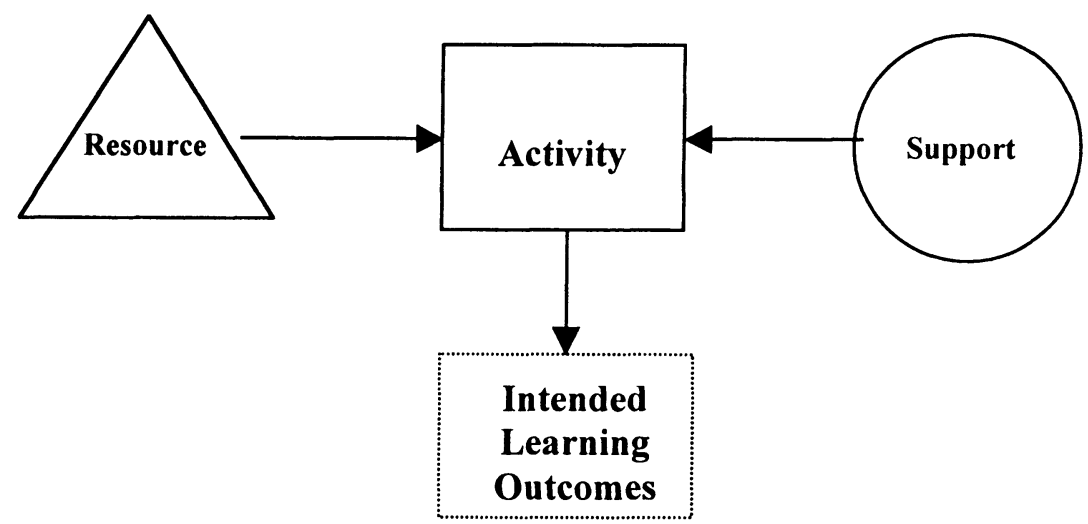

Figure 3. Representation of a learning sequence as resources, activities and supports 


\section{REUSABILITY DRIVING LEARNING ENVIRONMENT DESIGN}

The access to rich resources world-wide has resulted in significantly wider use, but has also helped to drive the broader view of reusability. The issue of reusability of learning environments and their associated components has now developed as a major agenda for learning with both reusability at the small content chunk level and the learning design level being investigated, but not necessarily in conjunction with one another. The current significant investment in content, described in terms of standards, which can be reused and re-purposed in education settings, is becoming a priority nationally and internationally. A myriad of learning objects are now being developed, through such projects as the Learning Federation initiative for development of a significant K-12 repository of curriculum specific learning objects (http://socci.edna.edu.au/ newcms/view_page.asp), CLOE, the Cooperative Learning Object Exchange of Ontario (http://cloe.on.ca), Merlot and a raft of digital libraries (Marlino \& Sumner, 2002).

Unfortunately, there is still a significant chasm between those researchers working on standards and describing and designing learning object metadata, and those interested in the learning settings in which these objects will need to be recombined as learning designs. Currently there seems to be two approaches to use of multimedia content in learning. The first is to develop learning designs based on our knowledge of best practice. This is a time consuming process and requires access to quality exemplars. Significant advances are being made through projects such as the SoURCE project: http://www.source.ac.uk/ which is developing instances of learning designs and theAUTC project described above on use of ICT in learning (Harper et al., 2000) which is developing mechanisms to streamline this process through generic learning designs and symbolic languages. However, these, and similar projects have not addressed reuse or management of resources in any specific way.

The second approach has evolved from information systems and is characterised by the current research in learning objects through learning technology standards. Standardization is a means to ensure interoperability between systems and this has been approached both through learning management systems and learning environments standardization initiatives. These initiatives, such as IEEE Learning Technology Standards Committee (LTSC), Instructional Management Systems (IMS) Project, or the Advanced Distributed Learning Network (ADLNET) have developed a broad range of standards, from high-level specifications for architectures to bindings for certain components. However, most of these approaches focus on the reuse of content. These specifications do not provide adequate concepts for 
modelling pedagogy. What is missing is a way of taking the advantages from both of these approaches and developing a new way forward which would revolutionise the eLearning space i.e. a way of bringing together the power of quality learning designs and the concepts of reusability of learning resources as learning objects or digital learning items.

\section{PEDAGOGICAL MODELS}

Koper (2001) and Pawlowski (2001) argue that the current representation of metadata does not provide an adequate representation of pedagogical concepts for the linking of learning objects described via standards and learning designs.. Additionally, there is no adequate mapping of contentoriented representation to a pedagogy-oriented representation. A variety of models are being developed to close the gap including a Tutorial Markup Language (TML) (Netquest, 2000) for development of tutorial systems. A more promising approach for the representation of pedagogical concepts is the Educational Modelling Language (EML) (Koper, 2001) which is based on a meta-model for pedagogical modelling. However, Pawlowski has argued that currently, there is no mapping to other standards such as SCORM and that in order to use both standards, a common framework needs to be specified such as the Essen Learning Model (ELM) (Pawlowski, 2000). The designers claim that this model serves as a base for a high-quality design of learning environments from a pedagogical and content perspective.

The difficulty with many of these models is that they do not differentiate the learner task, set in a particular context, from the learning supports and the learning resources which facilitate the learning experience, thus allowing use of digital libraries of digital items such as those described by Marlino and Sumner (2002). What is needed is a model that describes the central learner experience and provides an effective and real connection to digital learning objects in a framework that will be easy for trainers, instructors and teachers to use to construct rich learning experiences. Additionally, before teachers can have access to these resources, quality tools will need to be developed for their use.

\section{CONCLUSION}

Technology has the potential and demonstrated facility to support good pedagogy with a key outcome of this alliance high quality learning in rich educational settings. There is ample evidence to support this claim, but we 
often overlook the relationship between technology and pedagogy when new technologies become available. Learning objects have been the major focus of the current reusability debate, but much of the good work being done on learning designs as reusable objects is currently not being effectively addressed as part of the debate. For example, the tools for linking learning objects with quality learning designs are only now being conceptualised and there are very few examples available. The construct of learning objects is set to again require teachers to re-conceptualise learning experiences for their students, and require teacher preparation programs to support their students in developing the skills in design and well as tool use. We can all hope that Gavriel Salomon's call for new pedagogical models for the new affordances offered by this new technology will be taken up in higher education, particularly in teacher preparation, and in classrooms, with the reusability debate resulting in more efficient development of quality learning settings for learners.

\section{ACKNOWLEGEMENT}

The author would like to acknowledge that the section of this paper to do with the AUTC project, was made possible through participation in the 2000-2002 Australian Universities Teaching Committee project titled: "Information and Communication Technologies and Their Role in Flexible Learning" funded through the Higher Education Innovation Programme (HEIP) via the Commonwealth Department of Education, Science and Training. Consortium: Project Team - Professor Barry Harper (University of Wollongong), Professor Ron Oliver (Edith Cowan University), Professor John Hedberg (University of Wollongong), Professor Sandra Wills (University of Wollongong); Research Team - Dr Jan Herrington (Edith Cowan University), Dr Garry Hoban (University of Wollongong), Dr Lori Lockyer (University of Wollongong), Associate Professor Catherine McLoughlin (Australian Catholic University). For information about this project visit the project web site: http: //www.learningdesigns.uow.edu.au or contact: Project Manager, Dr Shirley Agostinho (University of Wollongong).

\section{REFERENCES}

Alexander, S. \& McKenzie, J. (1998). An Evaluation of Information Technology Projects for University Learning. Canberra: CAUT, AGPS.

Bonk, C. (1998). Pedagogical Activities on the "Smartweb": Mentoring Undergraduate Educational Psychology Students. Paper presented at the American Educational Research Annual Meeting, April 14, San Diego, CA. Retrieved September 11, 1998 from http://php.indiana.edu/ cjbonk/smart_paper.html

Boud, D. \& Prosser, M. (2001). Key Principles for High Quality Student Learning in Higher Education - From a Learning Perspective. Paper presented at a workshop held on April 27, 2001 for the AUTC funded project: Information and Communication Technologies and Their Role in Flexible Learning, Sydney, Australia. 
Bostock, S. (1998). Constructivism in mass education: A case study. British Journal of Educational Technology, 29(3), 225-240.

Brickell, G., (2002). Problem Solving in Technology Supported Learning Environments. Unpublished doctoral thesis, University of Wollongong.

Clarke, R. E. (1985). Evidence for confounding in computer-based instruction studies: Analyzing the meta-analyses. Educational Communications and Technology Journal, 33(4), 249-262.

Clarke, R. E. (1999). The cognitive science and human performance technology. In H. D. Stolovitsch \& E. J. Keeps, Handbook of Human Performance Technology (pp. 82-95). San Francisco: Jossey-Bass-Pfeiffer.

Corderoy, R., (2002). Designing Simulations to Improve Learning Outcomes in Ecological Education. Unpublished doctoral thesis, University of Wollongong.

Duffy, T. M. \& Cunningham, D. J. (1996). Constructivism: Implications for the design and delivery of instruction. In D. H. Jonassen (Ed.), Handbook of Research for Educational Communications and Technology (pp. 170-198). New York: Macmillan Library Reference USA.

Duschatel, P. \& Spahn, S. (1996). Design for Web-based Learning. Paper presented at the WebNet'96, World Conference of The Web Society, San Francisco, USA.

Exploring the Nardoo (1996). Canberra: Interactive Multimedia, Project Manager Barry Harper, Instructional Design Barry Harper, John Hedberg, Rob Wright, Grant Farr and Christine Brown (a CD ROM-based interactive multimedia package produced in collaboration with NSW Dept of Land and Water Conservation).

Gordon, J. (1998). Learning with Technology Tools. Unpublished doctoral thesis, University of Wollongong.

Grabinger, R. S. (1996). Rich environments for active learning. In D. H. Jonassen (Ed.), Handbook of Research for Educational Communications and Technology (pp. 665-692) New York: Macmillan Library Reference USA.

Hannafin, M. J. \& Land, S. M. (1997). The foundations and assumptions of technologyenhanced student centred learning environments. Instructional Science, 25, 167-202.

Harper, B., Hedberg, G. \& Wright, R. (2000a). Who benefits from virtuality? Computers and Education, 34, 163-176.

Harper, B., Squires, D. \& McDougall, A. (2000b). Constructivist simulations in the multimedia age. Journal of Educational Multimedia and Hypermedia, 9(2), 115-130.

Harper, B., Hedberg, J., Corderoy, R..\& Wright, R. (2000). Employing cognitive tools within interactive multimedia applications. In S. P. Lajoie (Ed.), Computers as Cognitive Tools: The Next Generation (pp. 227-245). Mahwah, NJ: Lawrence Erlbaum Publishers.

Hedberg, J., Harper, B., Lockyer, L., Ferry, B., Brown, C. \& Wright, R. (1998a). Supporting ill-structured problem solving in interactive multimedia learning environments. In $\mathrm{T}$. Ottmann \& I. Tomek (Eds.), Proceedings of ED-MEDIA/ED-TELECOM 98 World Conference on Educational Multimedia and Hypermedia \& World Conference on Educational Telecommunications (Vol. 1, pp. 496-501). Charlottesville, VA: Association for the Advancement of Computing in Education.

Hedberg, J., Harper, B., Lockyer, L., Ferry, B., Brown, C. \& Wright, R. (1998b). Supporting learners to solve ill-structured problems. In R. M. Corderoy (Ed.), Proceedings of the 15th Annual Conference of the Australasian Society for Computers in Learning in Tertiary Education (pp. 317-327). Wollongong, NSW: University of Wollongong.

IEEE Learning Technology Standards Committee (2000). Draft Standard for ComputerManaged Instruction (CMI), Version 3.4. Retrieved May 5, 2001 from http://ltsc.icee.org/doc/wg11/CMI-Sem34.doc 
IEEE Learning Technology Standards Committee (2001). Draft Standard for Learning Object Metadata, Version 6.1. Retrieved May 30, 2001 from http://ltsc.ieee.org/ doc/wg 12/LOMv6.1.html

Koper, R. (2001). Modeling units of study from a pedagogical perspective - the pedagogical meta-model behind EML. Retrieved July 1, 2001 from http://eml.ou.nl/ introduction/articles.htm

Levin, J. (1999). Dimensions of network-based learning. International Journal of Educational Technology, 2(1).

Marlino, M. \& Sumner,T. (2002). Educational digital libraries; building community; building libraries. Proceedings of ED-MEDIA 2002, World Conference on Educational Multimedia, Hypermedia \& Telecommunications (pp.1223-1225). Denver Colorado, USA: Association for the Advancement of Computing in Education.

Netquest (2000). Tutorial Markup Language (TML). Retrieved September 25, 2000 from http://www.ilrt.bris.ac.uk/netquest/liveserver/TML_INSTALL/doc/tml.html

Oliver, R. (1999). Exploring strategies for on-line teaching and learning. Distance Education, 20(2), 240-254.

Oliver, R. \& McLoughlin, C. (1999). Curriculum and learning-resource issues arising from the use of Web-based course support systems. International Journal of Educational Telecommunication, 5(4), 419-438.

Pawlowski, J. M. (2000). The Essen Learning Model - A Multi-Level Development Model. Staff and Education Development International, 4.

Pawlowski, J. M. (2001). Das Essener-Lern-Modell (ELM): Ein Vorgehensmodell zur Entwicklung Computerunterstützter Lernumgebungen [The Essen-Learning Model (ELM): A Development Model for the Development of Computer-Supported Learning Environments]. Unpublished dissertation. University of Essen, Germany.

Squires, D. (1996). Can multimedia support constructivist learning? Teaching Review, 4(2), 10-17.

Salomon, G. (1998). Novel constructivist learning environments and novel technologies: Some issues to be concerned with. Research Dialogue in Learning and Instruction, 1, 312.

Vygotsky, L. (1978). Mind in society. Cambridge, Massachusetts: Harvard University Press. 